\title{
Combustion Characteristics in Rotating Detonation Engines
}

\author{
Yuhui Wang $\mathbb{D},{ }^{1}$ Wenyou Qiao, ${ }^{2}$ and JialingLe ${ }^{3}$ \\ ${ }^{1}$ College of Mechanical and Electrical Engineering, Beijing University of Chemical Technology, Beijing, China \\ ${ }^{2}$ Southwest University of Science and Technology, Mianyang, China \\ ${ }^{3}$ China Aerodynamics Research and Development Center, Mianyang, China
}

Correspondence should be addressed to Yuhui Wang; aowuki@163.com

Received 25 August 2020; Revised 9 February 2021; Accepted 22 February 2021; Published 15 March 2021

Academic Editor: William Yeong Liang Ling

Copyright (c) 2021 Yuhui Wang et al. This is an open access article distributed under the Creative Commons Attribution License, which permits unrestricted use, distribution, and reproduction in any medium, provided the original work is properly cited.

\begin{abstract}
A lot of studies on rotating detonation engines have been carried out due to the higher thermal efficiency. However, the number, rotating directions, and intensities of rotating detonation waves are changeful when the flow rate, equivalence ratio, inflow conditions, and engine schemes vary. The present experimental results showed that the combustion mode of a rotating detonation engine was influenced by the combustor scheme. The annular detonation channel had an outer diameter of $100 \mathrm{~mm}$ and an inner diameter of $80 \mathrm{~mm}$. Air and hydrogen were injected into the combustor from 60 cylindrical orifices in a diameter of $2 \mathrm{~mm}$ and a circular channel with a width of $2 \mathrm{~mm}$, respectively. When the air mass flow rate was increased by keeping hydrogen flow rate constant, the combustion mode varied. Deflagration and diffusive combustion, multiple counterrotating detonation waves, longitudinal pulsed detonation, and a single rotating detonation wave occurred. Both longitudinal pulsed detonation and a single rotating detonation wave occurred at different times in the same operation. They could change between each other, and the evolution direction depended on the air flow rate. The operations with a single rotating detonation wave occurred at equivalence ratios lower than 0.60 , which was helpful for the engine cooling and infrared stealth. The generation mechanism of longitudinal pulsed detonation is developed.
\end{abstract}

\section{Introduction}

Detonation engines theoretically have higher thermal efficiency than deflagration engines (i.e., conventional engines, such as rocket engines and air-breathing engines) since detonation has a lower entropy production than deflagration. A rotating detonation engine (RDE) is one type of detonation engine being widely studied [1-6]. There may be one or several rotating detonation waves (RDWs) moving tangentially in the RDE combustor [7]. Chemical reactions mainly occur inside the detonation wave, although there may still be deflagrative combustion near the walls [8] or between the reactants and products [9]. The rotating propagation and pressure-gain combustion together make the detonation wave continuous. The preliminary tests of an $\mathrm{RDE}$ without any nozzle were carried out to evaluate the propulsion performance, and a vacuum specific impulse of $341.7 \mathrm{~s}$ for hydrogen-oxygen mixture was obtained [10]. Theoretically, RDEs may have $20 \%$ to $25 \%$ higher thermal efficiency than deflagration engines by exploiting the advantages of detonative combustion [11]. RDE combustion tests using ethylene and oxygen were demonstrated towards the sounding rocket experiment in space, and $73 \%$ to $90 \%$ of optimum specific impulse was achieved for the RDE with converging nozzle [12]. Aerojet Rocketdyne conducted 524 hot fire tests until 2014, including multiple propellants (both gaseous and liquid fuels), multiple injectors, and multiple nozzles, with and without transient plasma augmentation [13].

The Air Force Research Laboratory and Innovative Scientific Solutions Inc. has obtained a significant amount of experimental data from RDEs, including specific impulse, $\mathrm{OH} *$ chemiluminescence images, high-frequency heat flux measurements, and accurate pressure measurements from inside the detonation channel. Operation with gaseous hydrocarbon/air propellants provided the expected levels of propulsion performance, although there are still numerous technical problems to be solved if heavier hydrocarbon fuels are to be detonated in an $\mathrm{RDE}$ [14]. The $\mathrm{OH} *$ 
chemiluminescence images were used to study the effects of the air mass flow rate, equivalence ratio, air injection area, and fuel injection scheme on the rotating detonation structure $[15,16]$. For fuel-lean conditions, the high $\mathrm{OH} *$ emissions from the detonation were distributed more broadly in space. The wave front was more concave with respect to the fuel fill region in front of the detonation as the air injection slot was increased from low to intermediate values. The angle between the wave front and fuel injection surface in front of the detonation became more acute as the air injection slot was increased. Reducing the number of fuel injection holes had significant effects on the detonation structure including transition from one wave to two waves. Heat flux could peak at values below $1 \mathrm{MW} / \mathrm{m}^{2}$ at the base of the detonation channel and over $25 \mathrm{MW} / \mathrm{m}^{2}$ around the detonation wave front $[17,18]$. A pressure measurement technique employing an underexpanded jet structure external to an RDE was attempted, and the peak pressure within the detonation channel was estimated to be about $2.63 \pm 0.46 \mathrm{MPa}$ on average [19], which was more accurate than that obtained by dynamic sensors. The Air Force Research Laboratory also developed the first successful air-breathing premixed RDE, for which a technique of backfire suppression was necessary [20]. Fuel-air mixing affected RDE operation greatly, as known from different operations between premixed and nonpremixed RDEs. The different operations between premixed and nonpremixed RDEs were because diffusive mixing could provide a small range of highly detonable mixture over a wider range of global mass flow rates.

There are a few kinds of rotating detonation waves, including corotating detonation waves, counterrotating detonation waves, and a single RDW [21-24]. The single RDW may be thought of as a special kind of corotating detonation waves that are roughly stable. Counterrotating detonation waves usually make the detonations weak or strong at times and unstable. This condition is not desirable for operating of an RDE, as it is caused by incomplete mixing [15]. Higher air mass flow rates tend to make more RDWs, and at a given flow rate, the number of waves depends on the overall equivalence ratio [25]. For the RDWs, four different combustion patterns exist: one wave, two corotating waves, one couple in counterrotating mode, and two couples in counterrotating mode [26]. Longitudinal pulsed detonation (LPD) could also occur in an RDE and propagate axially [27, 28]. Anand et al. concluded that LPD was caused by a peculiar detonation initiation mechanism enabled by a reflected shock wave from the RDE exit and LPD moved downstream. The LPD frequency depended on the initial combustor pressure and equivalence ratio, with higher frequency observed with an increase in backpressure and equivalence ratio. They also concluded that LPD did not exist when there was no throat at the RDE exit. However, Frolov et al. thought LPD moved upstream since reactive shock waves were initiated near the combustor outlet. Moreover, LPD was found in an RDE without a throat at the exit in this study. Therefore, the generation mechanism of LPD should be studied further. Three modes of operation were noted in other studies. Operations of detonation, acoustic pulsations, and deflagration were found in the study [29]. The acoustic pulsations were actually the longitudinal pulsed detonation referred to above. Harmonic axial pulsing preceded every observed deflagration to detonation transition.

In this study, air flow rates with a constant hydrogen flow rate of $10 \mathrm{~g} / \mathrm{s}$ were varied to investigate the combustion features of an RDE. The tests also simulated the effects of changeful air flow on the engines during the flight. It showed that the combustion in an RDE tends to be affected by the combustor structure since the structure had a great effect on the mixing of the fuel and oxidant. A stable single RDW with a short exhaust plume occurred in the fuel-lean conditions with equivalence ratios lower than 0.6 , operation conditions that are beneficial for an RDE to be applied as an airbreathing engine. Multiple corotating detonation waves never occurred in the range of air flow rates $72-740 \mathrm{~g} / \mathrm{s}$ at a hydrogen flow rate $10 \mathrm{~g} / \mathrm{s}$.

\section{Experimental Facility and Methodology}

The experimental setup and its schematic are shown in Figure 1. The experimental system mainly consists of a gas supply section, a data acquisition section, a control section, an ignition section, and a combustor. The trunk stream is the flow of reactants directly into the combustor, and the tributary is the flow into the combustor through the predetonator. The gas supply system, supplying hydrogen and oxygen to the predetonator and hydrogen-air to the combustor, includes gas sources, reduction valves, check valves, solenoid valves, mass flow meters, and pipes. The gas sources include one bottle of oxygen, six bottles of hydrogen, and one large can of compressed air. The hydrogen source can provide a flow at the maximum total pressure of $12 \mathrm{MPa}$. The air source can provide a flow at the maximum total pressure of 10.5 MPa. The reduction valves are able to maintain a constant pressure at the valve exit. The check valves prevent backflow. The solenoid valves are controlled by the computer program. Mass flow meters measure the mass flow rates by sonic nozzles and pressure sensors.

The data acquisition section acquiring pressure signals consists of PCB dynamic pressure sensors 113B24, Keller pressure sensors PA-23SY, a high speed camera, and a data recorder. Two PCB pressure sensors labeled as S1 and S2 in Figure 1 are mounted in the combustors at the same axial position as that of the predetonator. The angle between them along the combustor circumference is $180^{\circ}$. The sensors are coated with silicone to protect them from the high temperature of detonation products. The sampling frequency is $1 \mathrm{MHz}$. The ignition section consists of a high-energy spark plug and a predetonator with a length of $200 \mathrm{~mm}$ and an inner diameter of $10 \mathrm{~mm}$. The ignition frequency is $28 \mathrm{~Hz}$, and ignition time lasts for $50 \mathrm{~ms}$. The predetonator is tangentially connected with the combustor to make the detonation wave move into the combustor asymmetrically. At the start-up stage, hydrogen and oxygen from the gas supply system flow into the predetonator, to be ignited by the spark plug mounted at the head of the predetonator. A deflagration wave is produced by the ignition and develops into a detonation wave gradually in the predetonator, a process denoted deflagration to detonation transition (DDT). Then, the 


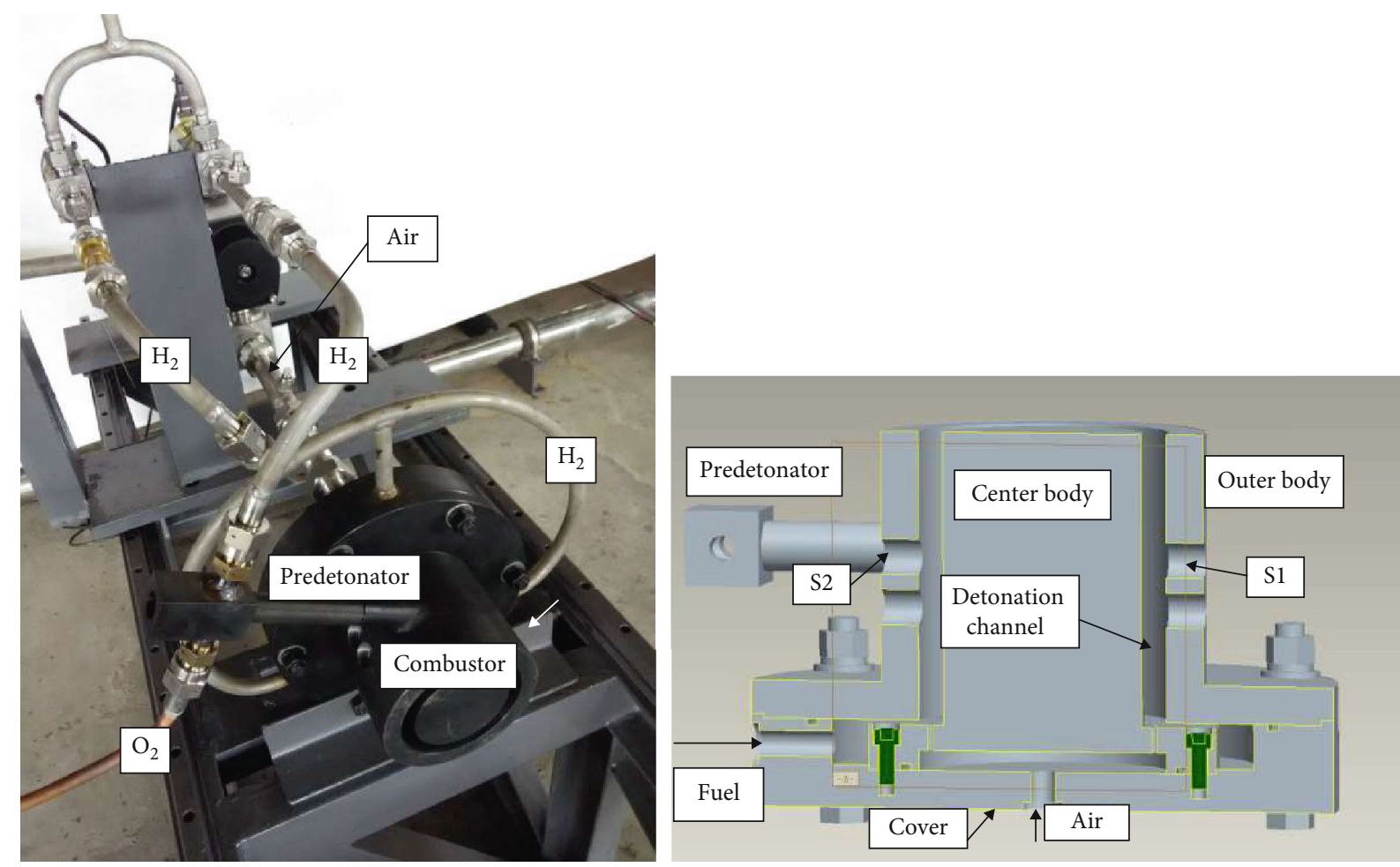

FIGURE 1: Experimental setup and combustor schematic.

TABLE 1: Air mass flow rate, combustion mode, and RDW velocity for different equivalence ratios at the hydrogen mass flow rate $10 \mathrm{~g} / \mathrm{s}$.

\begin{tabular}{lccc}
\hline Air flow $(\mathrm{g} / \mathrm{s})$ & Equivalence ratio & Combustion mode & RDW velocity $(\mathrm{m} / \mathrm{s})$ \\
\hline 72 & 4.78 & Deflagration and diffusive combustion & NA \\
103 & 3.35 & Deflagration and diffusive combustion & NA \\
135 & 2.56 & MCRDWs & NA \\
175 & 1.97 & MCRDWs & 970 \\
215 & 1.60 & MCRDWs & 949 \\
255 & 1.35 & MCRDWs & 959 \\
286 & 1.21 & MCRDWs & 916 \\
350 & 0.99 & MCRDWs & 872 \\
398 & 0.87 & MCRDWs & 659 \\
430 & 0.8 & MCRDWs & 594 \\
469 & 0.74 & LPD & NA \\
510 & 0.68 & LPD & NA \\
541 & 0.64 & SRDW & 1210 \\
573 & 0.60 & LPD & NA \\
605 & 0.57 & SRDW & 1222 \\
636 & 0.54 & SRDW & 1222 \\
776 & 0.51 & SRDW & 1215 \\
740 & 0.49 & SRDW & 1208 \\
\hline
\end{tabular}

detonation wave moves into the combustor tangentially and finally keeps rotating around the annular combustor. The combustor has the following main geometric parameters: annular channel outer diameter of $100 \mathrm{~mm}$, channel length of $117 \mathrm{~mm}$, and channel width of $10 \mathrm{~mm}$. Air is injected axially into the channel through 60 holes of $2 \mathrm{~mm}$ diameter.
Hydrogen is injected centripetally into the channel through a circumferential slot of $2 \mathrm{~mm}$ width. Hydrogen and oxygen are, respectively, $1 \mathrm{~g} / \mathrm{s}$ and $8 \mathrm{~g} / \mathrm{s}$ for the tributary.

The time sequence ensures there is already a trunk stream of reactants in the combustor before the detonation wave is injected from the predetonator. Also, before the ignition, 


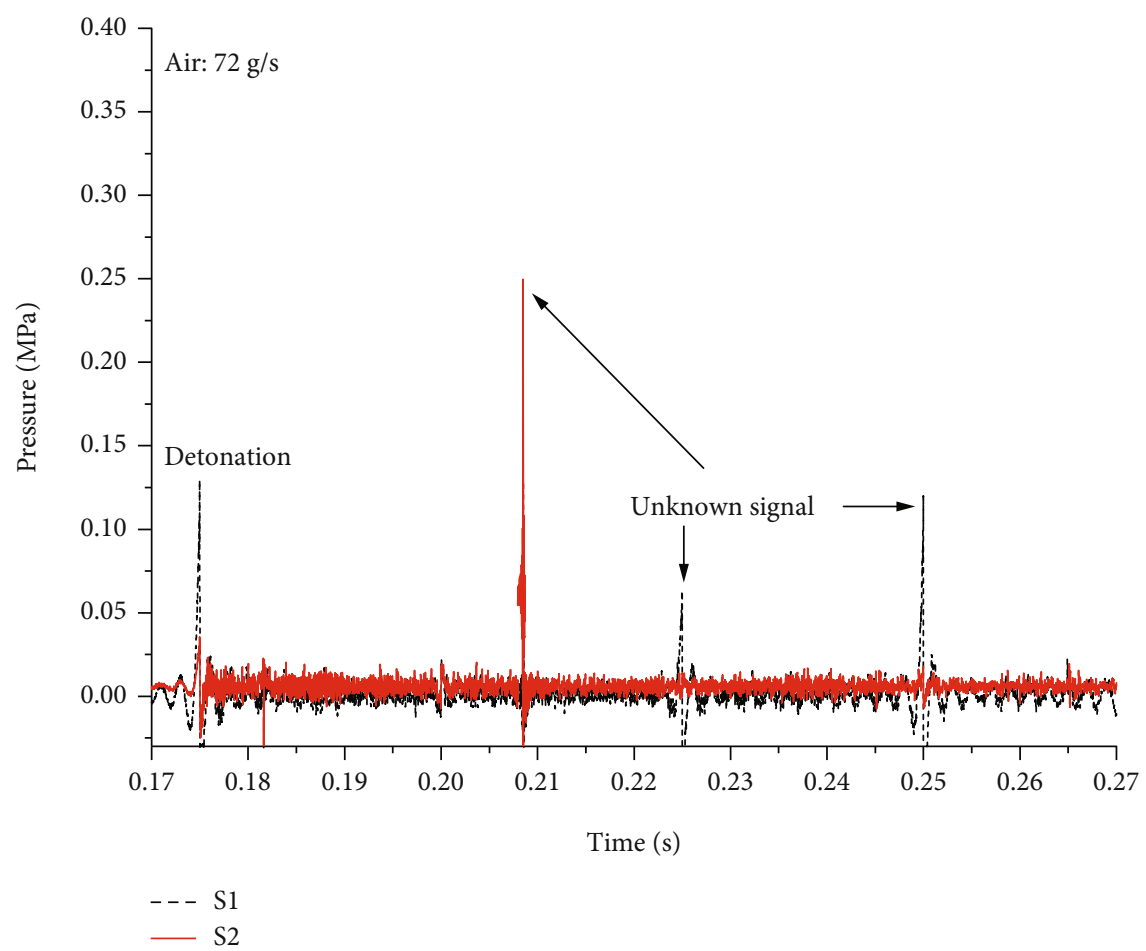

(a) Global view

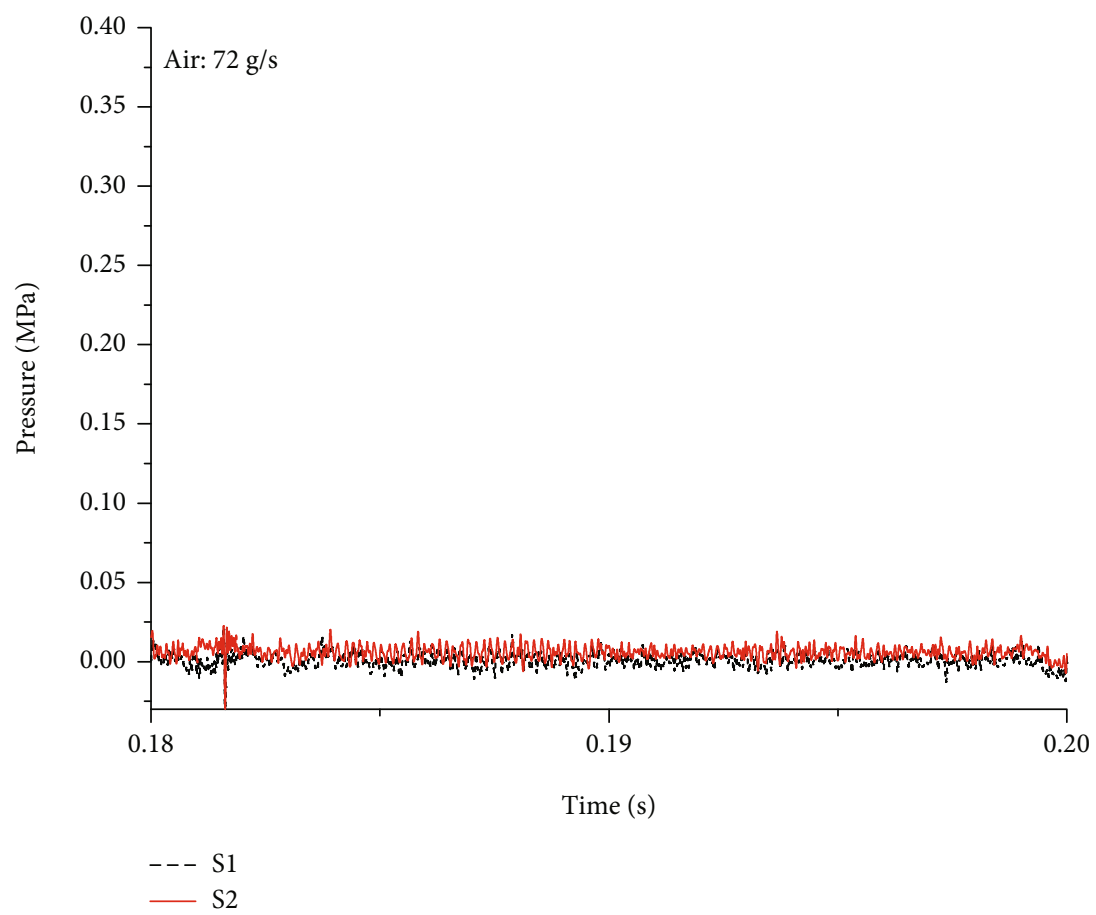

(b) Close-up view

FIgURe 2: Pressure traces obtained by S1 and S2 for the air mass flow rate $72 \mathrm{~g} / \mathrm{s}$.

there are enough reactants in the predetonator for the detonation wave to be formed. The tributary is used to detonate the trunk stream, and it is cut off after ignition. The ignition, tributary, and trunk stream last for $0.050 \mathrm{~s}, 0.100 \mathrm{~s}$, and $0.700 \mathrm{~s}$, respectively.

\section{Results and Discussion}

Table 1 shows the equivalence ratio, combustion mode, and RDW velocity for different air mass flow rates during the steady phase. MCRDWs, SRDW, and LPD denote multiple 

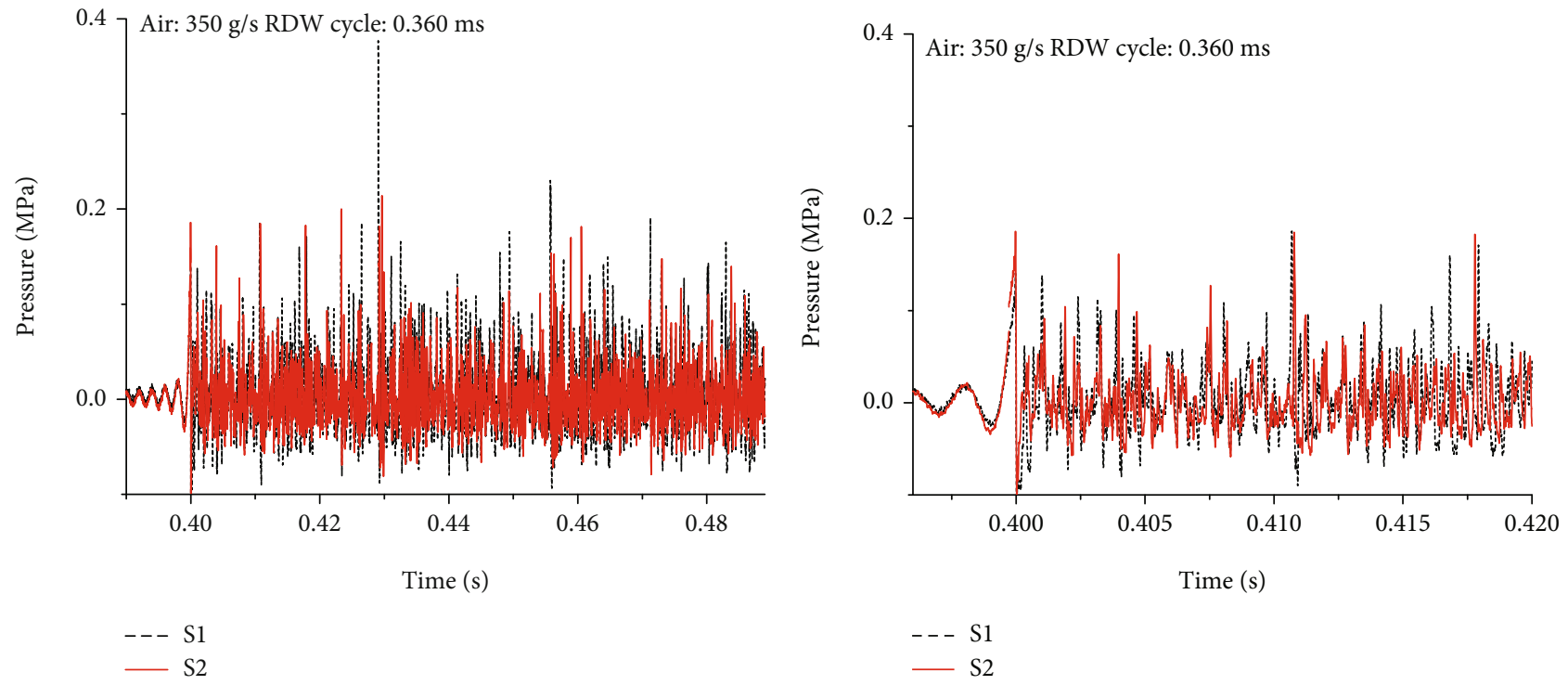

(a) Global view

(b) Close-up view

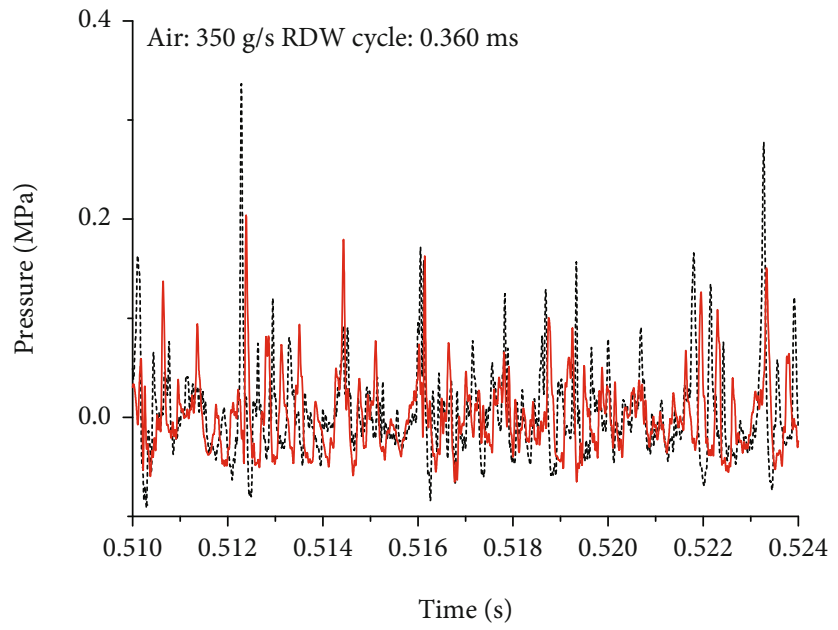

-- S 1

- S2

(c) Close-up view

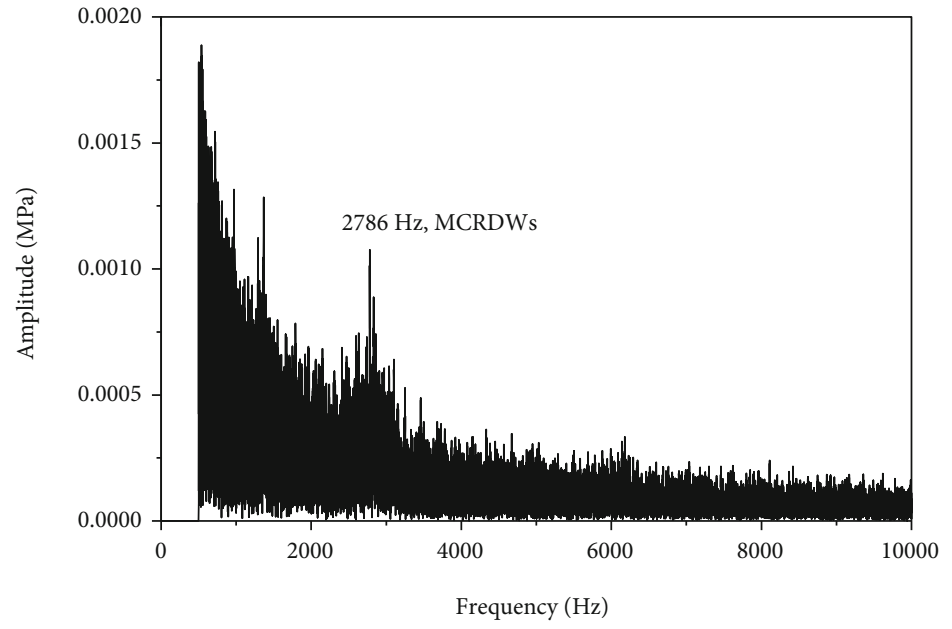

(d) Fast Fourier transformation for S1

FIgURE 3: Pressure traces obtained by $\mathrm{S} 1$ and $\mathrm{S} 2$ for the air mass flow rate $350 \mathrm{~g} / \mathrm{s}$. 


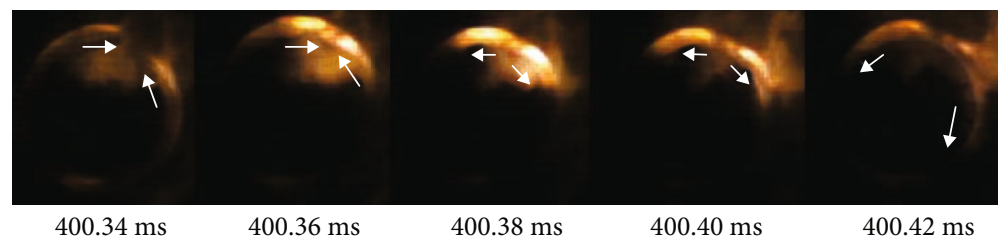

Figure 4: Rotating detonation events captured by a high-speed camera, 50000 fps.

counterrotating RDWs, a single RDW with a velocity of about $1200 \mathrm{~m} / \mathrm{s}$, and longitudinal pulsed detonation, respectively. A single RDW produced roughly regular and periodic pressure traces, whereas multiple counterrotating RDWs produced irregular pressure traces because the RDW collisions often made the RDWs unstable and become stable again by themselves. The combustion mode discussed in the present study was for the steady phase if not specified. NA denotes "not applicable," meaning that there was no rotating detonation. The RDW velocity was calculated by the outer diameter of $100 \mathrm{~mm}$ of the detonation channel and the mean cycle between two neighboring pressure peaks recorded by PCB pressure sensors during the steady phase. The flow field was roughly steady at the steady phase. The transient phase was the start-up process, during which the flow field changes greatly. This transient phase also made the RDW unstable. Shutdown process was not discussed here.

3.1. Deflagration and Diffusive Combustion. Deflagration and diffusive combustion occurred outside the combustor for the air mass flow rate range of $72-103 \mathrm{~g} / \mathrm{s}$ (condition A). The run of the air mass flow rate $72 \mathrm{~g} / \mathrm{s}$ was analyzed for instance here. The pressure trace in Figure 2 was irregular, and the pressure was very low, indicating RDWs were not formed. Also, the exhaust plume for the air flow rate $72 \mathrm{~g} / \mathrm{s}$ was very long and had a length about $1.5 \mathrm{~m}$, indicating the combustion existed outside the combustor. The combustor end, acting as a bluff body, stabilized the deflagration, and diffusive combustion was caused by the unburned fuel mixed with the ambient air. It was the diffusive combustion that led to a long exhaust plume. Since the combustion was outside the combustor, the thrust was low and it did not meet the conditions necessary for engine operation. It was easy to understand that detonation could not be formed when the equivalence ratio was too high. Actually, the pressure sensors measured the steady flow without combustion in the combustor, but the PCB dynamic pressure sensors could not capture static pressure. Thus, the pressure in Figure 2 was nearly zero. It was noted that the detonation occurred during the start-up process but was not maintained. The unknown signals were random and might be electromagnetic interference.

3.2. Multiple Counterrotating RDWs. Multiple counterrotating RDWs (MCRDWs) occurred for the air mass flow rate range of $135-430 \mathrm{~g} / \mathrm{s}$ (condition $\mathrm{B}$ ). The collisions among the multiple RDWs caused the average RDW velocity to be lower than $1000 \mathrm{~m} / \mathrm{s}$. Typical pressure traces for such a condition are shown in Figure 3 for the air mass flow rate of $350 \mathrm{~g} / \mathrm{s}$. The pressure peaks changed significantly all the time and were not periodic because of the RDW collisions during most of the time. The RDW collision event was further confirmed by high-speed images in Figure 4 (exposure time $1 / 50000 \mathrm{~s}$ ). There were three RDWs at $400.34 \mathrm{~ms}$, but the one below was not observed after $400.34 \mathrm{~ms}$, perhaps because it became too weak to be captured. The arrows indicated the moving directions of RDWs. When two RDWs collided with each other during 400.36-400.40 ms, the reaction rate and temperature increased and the colliding zone was very luminous. After the collision, RDWs became stable and slightly dark. Collisions caused mechanical energy loss and lower average velocities for MCRDWs than SRDW shown in Table 1. In fact, condition B was nearly stoichiometric or slightly rich in hydrogen. Therefore, the ignition energy for the reactants was lower for this condition and the explosions were more easily initiated by shock waves which were common in RDEs [22]. Explosions induced two new counterrotating RDWs, one of which met the old RDW. The explosions were frequent and so were the RDW collisions, resulting in irregular pressure peaks such as those in Figure 3. Though the pressure peaks did not have good periodicity, there was still a dominant frequency of $2786 \mathrm{~Hz}$ shown in Figure 3(d). The flow field in the condition was unsteady, and the detonation was not fully developed because of collisions. Therefore, the detonation efficiency was not high enough, which could not take full advantage of detonative combustion.

3.3. Longitudinal Pulsed Detonation. Longitudinal pulsed detonation (LPD) occurred in the combustor for the air mass flow rate range of $469-510 \mathrm{~g} / \mathrm{s}$ (condition C). For example, the pressure peaks of S1 and S2 for $510 \mathrm{~g} / \mathrm{s}$ in Figure 5(c) were coincident, indicating that the detonation wave moved axially rather than tangentially since S1 and S2 had different azimuthal positions but the same axial positions. The LPD cycle of $0.443 \mathrm{~ms}$ in Figure 5(a) agreed approximatively with the frequency of $2244 \mathrm{~Hz}$ in Figure 5(d). However, the transient phase had a slightly higher detonation pressure and a shorter cycle than the steady phase because a single rotating detonation wave (SRDW) existed during the transient phase. The SRDW was confirmed by the alternate peaks of S1 and S2 in Figure 5(b). The S1 peaks were roughly the midpoints between two neighboring S2 peaks, as agreed with a relation that the sensors S1 and S2 had an angle of 180 degrees. LPD was usually a weak detonation wave not well developed since the length of the detonation channel was only $117 \mathrm{~mm}$ and the DDT (deflagration to detonation transition) took up only a part of the length, whereas an RDW was usually stable and strong enough since the rotating length was infinite. When the single RDW was weakened by some unknown shock waves and blown away, LPD occurred. LPD was caused by 


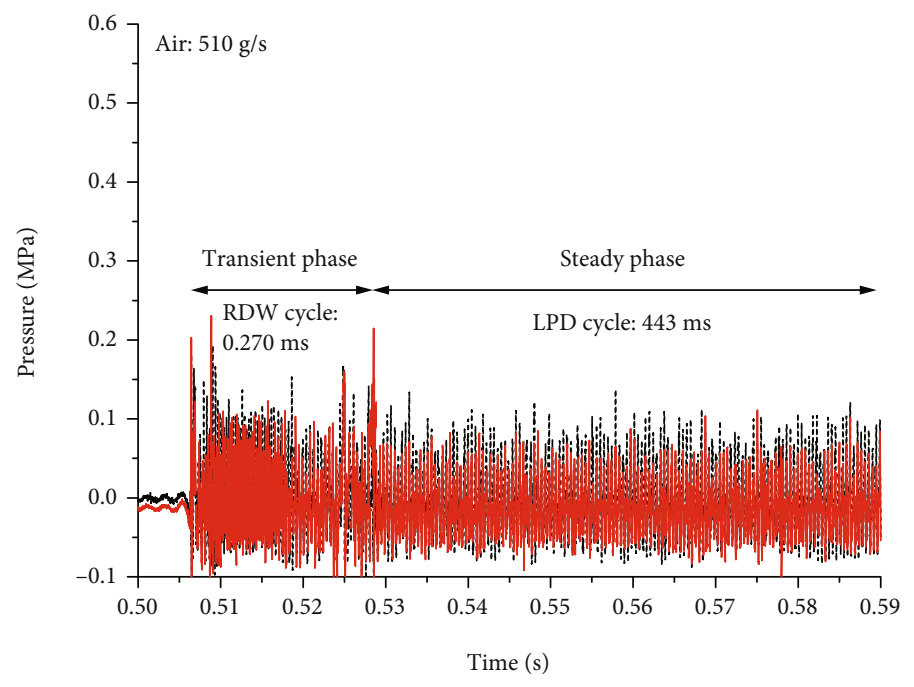

$$
---S 1
$$

(a) Global view

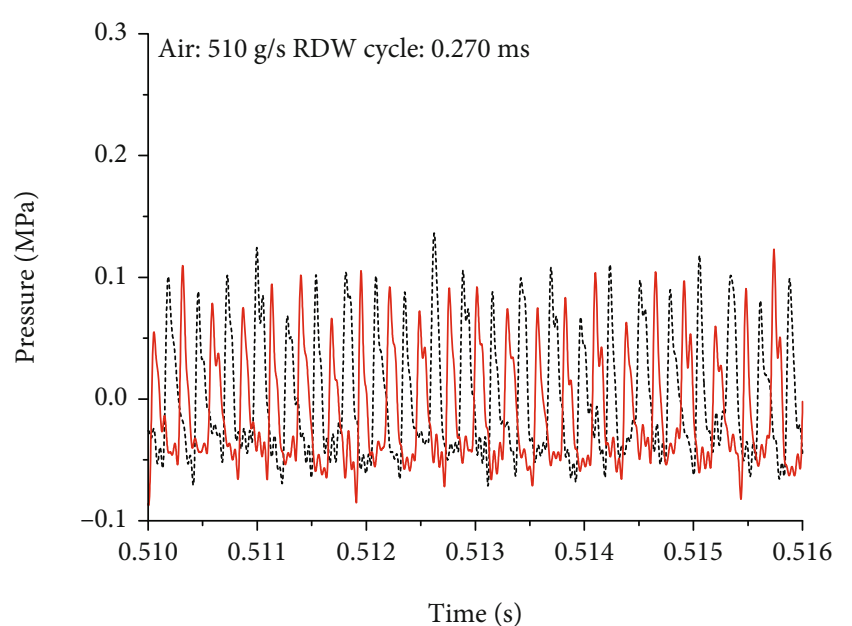

--- S1

- S2
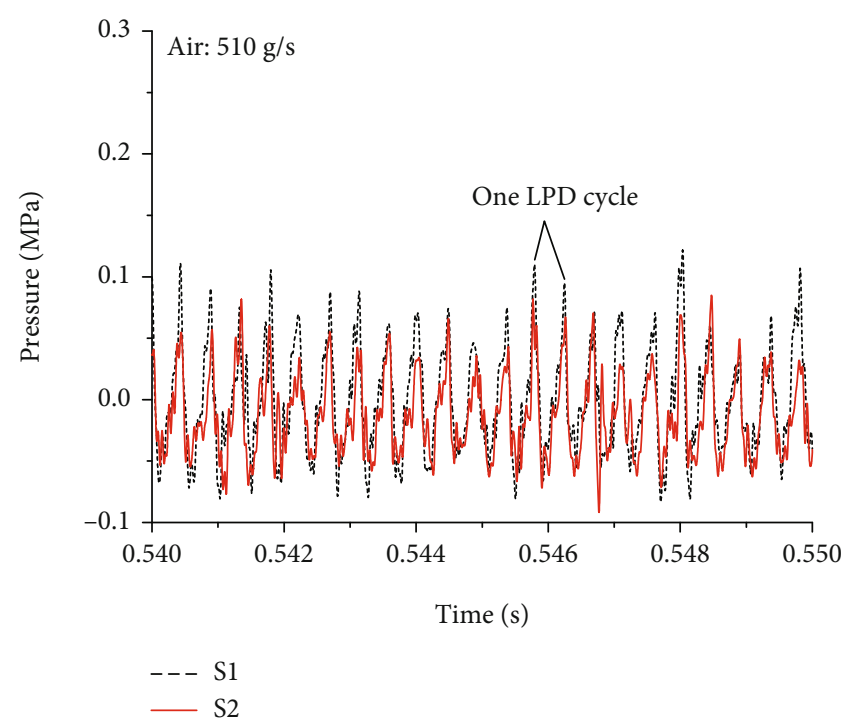

(c) Steady phase, LPD

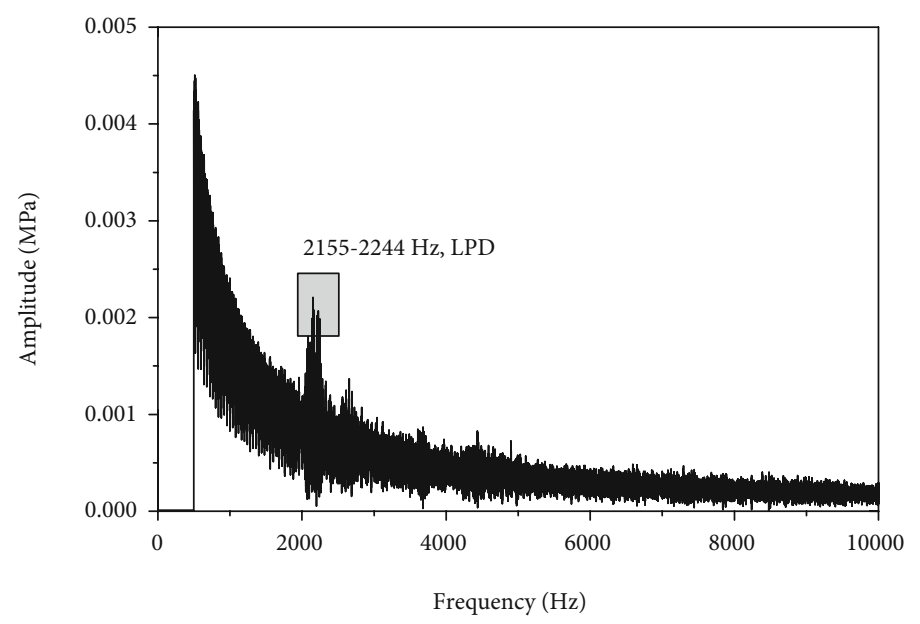

(d) Fast Fourier transformation for S1

Figure 5: Pressure traces obtained by S1 and S2 for the air mass flow rate $510 \mathrm{~g} / \mathrm{s}$. 


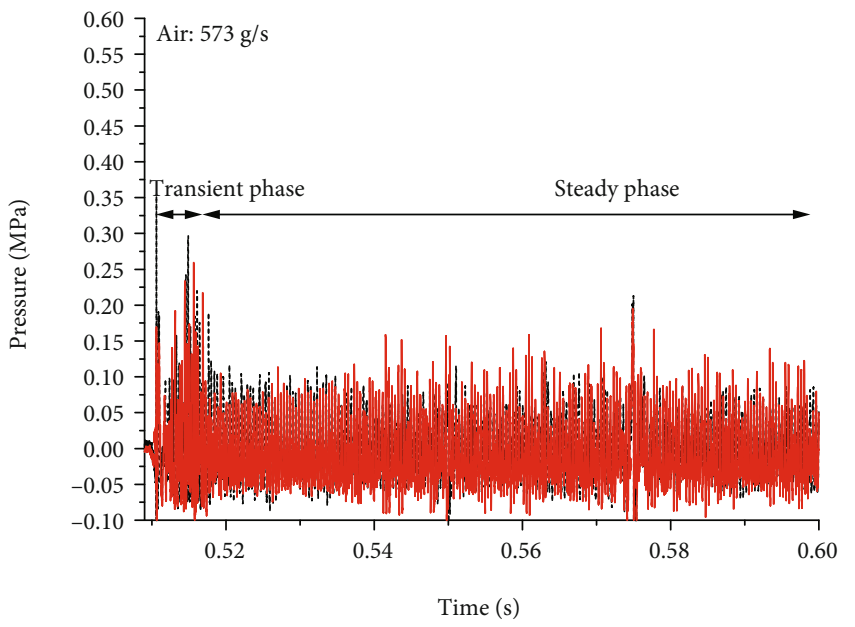

$--\mathrm{S} 1$

$-\mathrm{S} 2$

(a) Global view

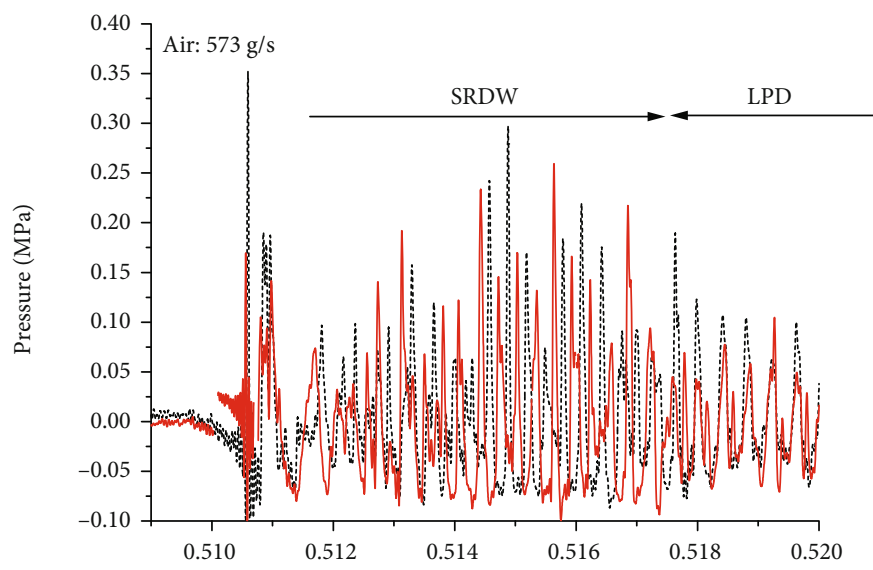

$---S 1$

Time (s)

$-\mathrm{S} 2$

(b) Transient phase

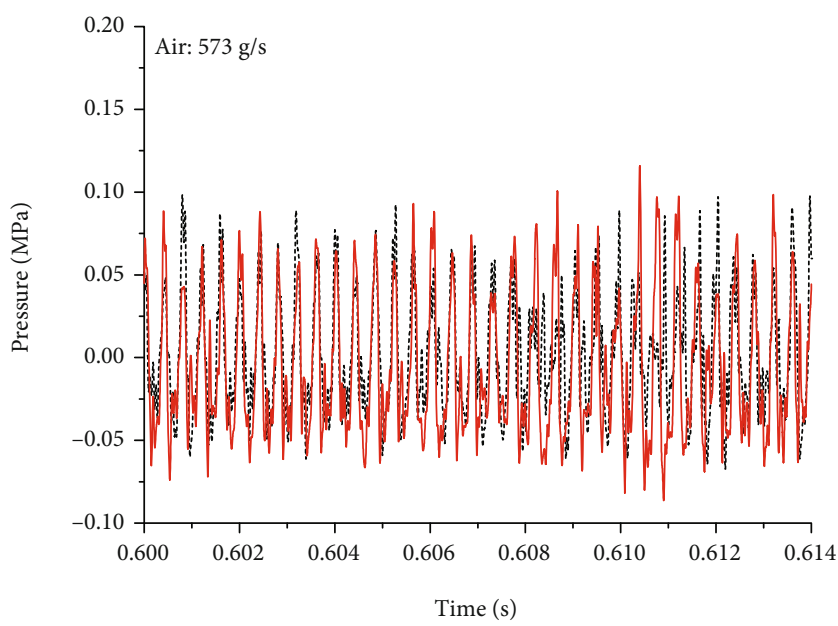

$---\mathrm{S} 1$

$-\mathrm{S} 2$

(c) Steady phase, LPD

Figure 6: Pressure traces obtained by S1 and S2 for the air mass flow rate $573 \mathrm{~g} / \mathrm{s}$. 


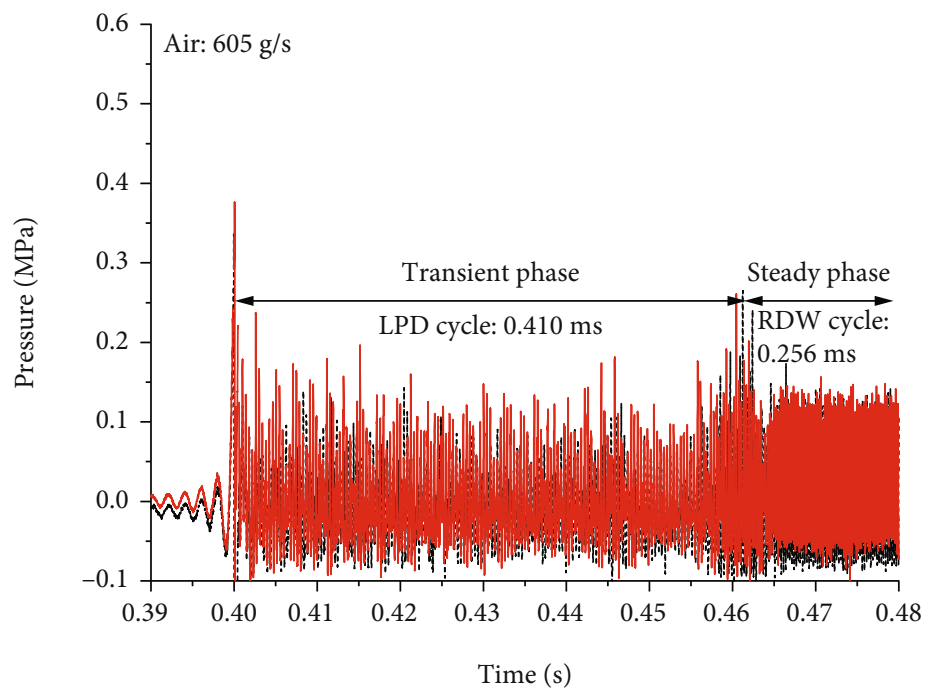

--- $\mathrm{S} 1$

(a) Global view

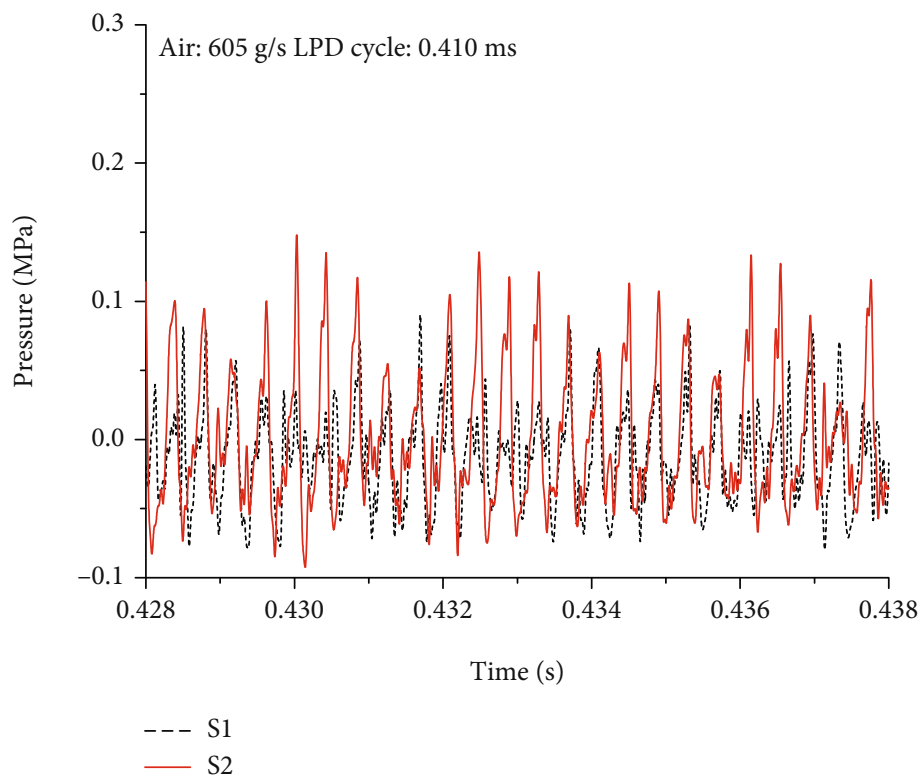

(b) Transient phase, LPD

Figure 7: Continued. 


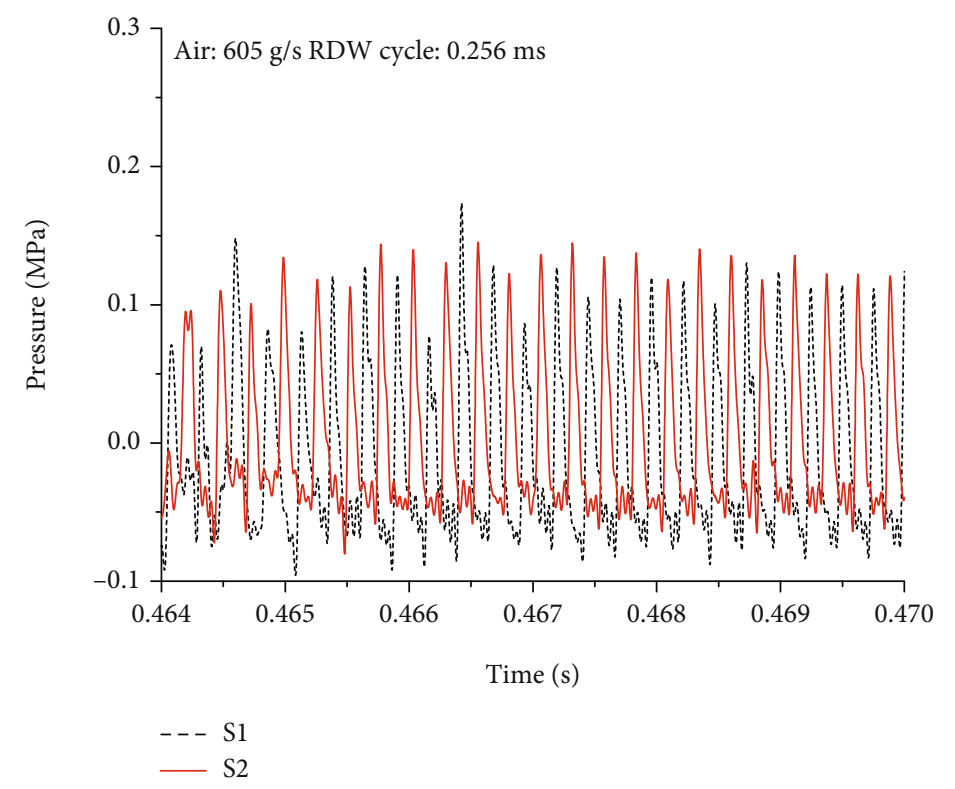

(c) Steady phase, SRDW

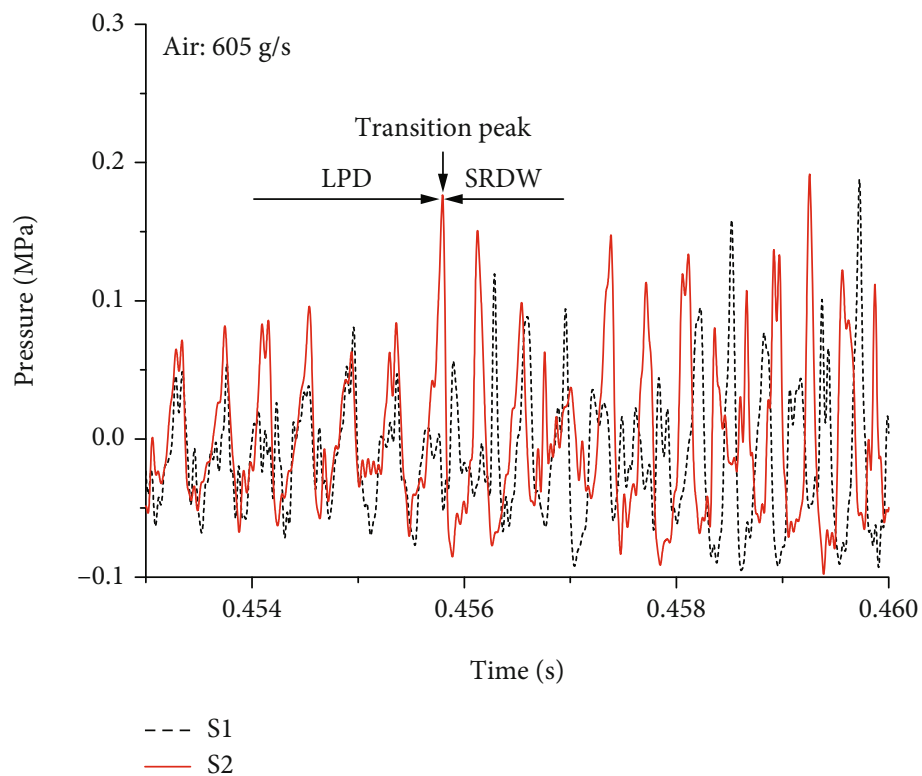

(d) Transition from LPD to SRDW

Figure 7: Pressure traces obtained by S1 and S2 for the air mass flow rate $605 \mathrm{~g} / \mathrm{s}$.

the reflected wave from the choked RDC (rotating detonation combustor) exit and did not exist when there was no throat at the RDC exit [27]. However, LPD was also discovered in the reference [26] in which there was no throat at the RDC exit, but the generation mechanism was not detailed. In addition, there was also no throat at the RDC exit in the present study. Thus, the generation mechanism of LPD should be supplemented. LPD causes backflow and great flow losses, reducing the propulsion performance. LPD is detrimental for the application of rotating detonation engines.

Longitudinal pulsed detonation occurred during the steady phase for the air mass flow rate of $573 \mathrm{~g} / \mathrm{s}$, as shown in Figure 6(c). It was difficult to understand why this happened in the flow rate range of condition $\mathrm{D}$, which was for a single RDW with a velocity of around $1200 \mathrm{~m} / \mathrm{s}$. In fact, the air flow rates of 541, 573, and $605 \mathrm{~g} / \mathrm{s}$ were three points at which the combustion mode changed from LPD to SRDW, as known in Table 1. Thus, the runs for the three flow rates were not robust and tended to be influenced by unknown perturbations, causing the combustion modes to be changed.

3.4. Single RDW. The single RDW (SRDW) occurred and had a velocity around $1200 \mathrm{~m} / \mathrm{s}$ for the air mass flow rate range of 541-740 g/s (condition D). The RDW velocities were 72\%$75 \%$ of CJ values. A reduced effective reaction rate, purportedly caused by turbulence induced reaction zone enlargement, produced the low wave speed [30]. The results are shown in Figures 7 and 8. Operations of higher air mass flow 


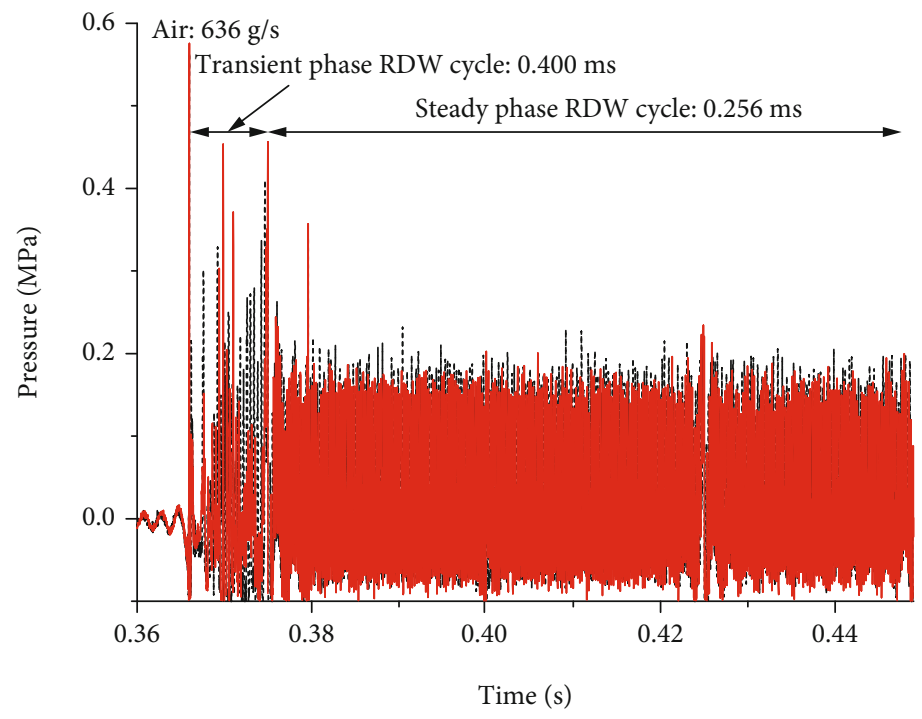

$---\mathrm{S} 1$

$-\mathrm{S} 2$

(a) Global view

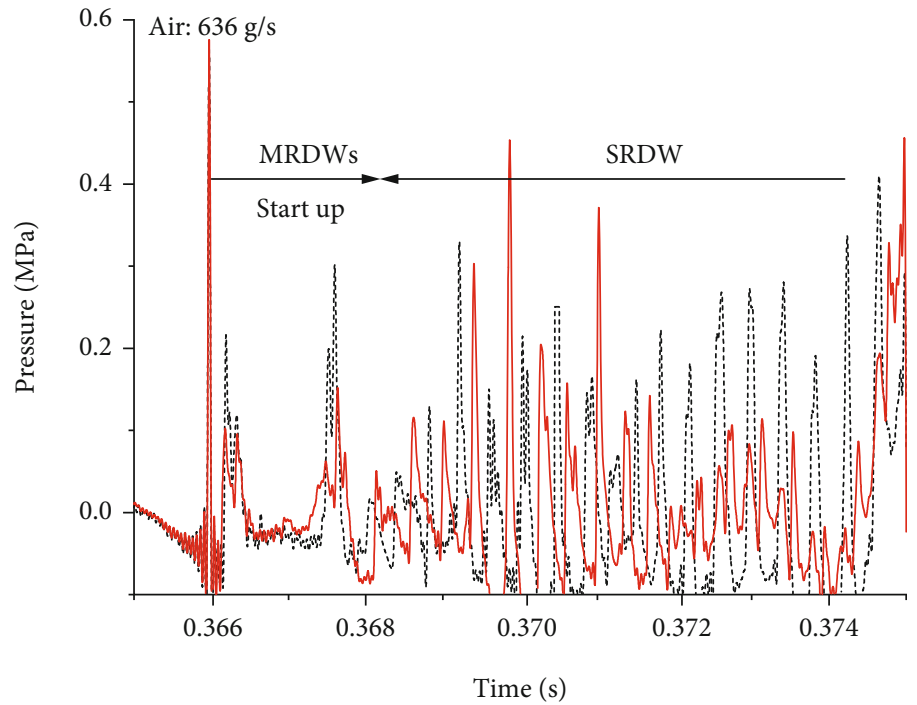

(b) Transient phase, unstable SRDW

Figure 8: Continued. 


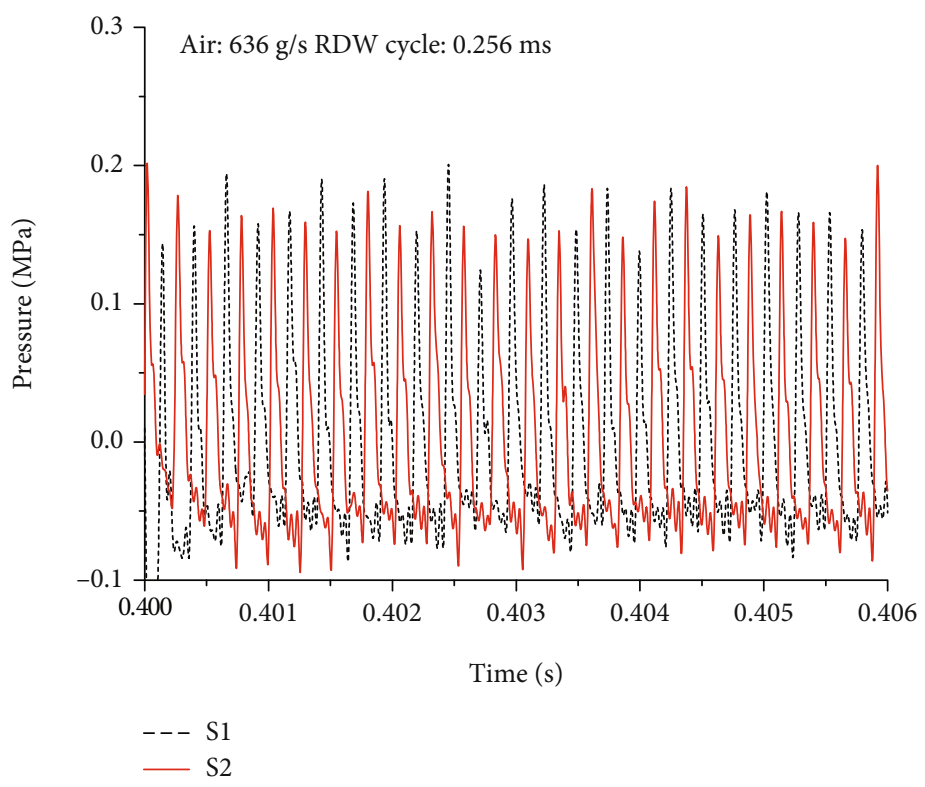

(c) Steady phase, SRDW

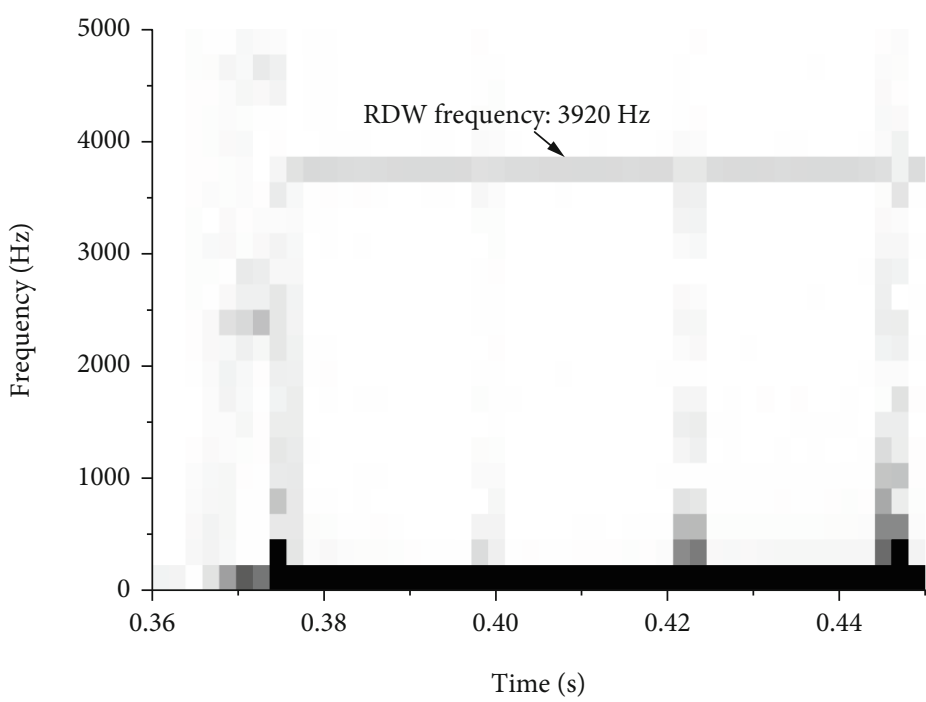

(d) Short-time Fourier transform

FIgure 8: Pressure traces obtained by S1 and S2 for the air mass flow rate $636 \mathrm{~g} / \mathrm{s}$ and short-time Fourier transform for the pressure trace S1.

rates were not conducted since it was limited by the experimental setup. It was difficult to ignite the reactants in the fuel lean condition, and new RDWs could not be induced by shock waves. Therefore, a single RDW was maintained rotating stably in the combustor for condition $\mathrm{D}$. The RDW velocity was decreased with the decreased equivalence ratio for condition D. A divergent RDW was formed when the detonation wave moved into the detonation channel from the predetonator, because the detonation channel was full of reactants at the ignition time. The divergent RDW contained two counterrotating fronts and two fronts, respectively, moving upstream and downstream. The two counterrotating RDW fronts collided with each other. The front moving upstream collided with the combustor head wall and caused a reflected shock wave. The RDW collisions and the reflected shock wave together made the pressure peaks irregular and not periodic at the start-up time in Figure 8(b). A single RDW was formed permanently after the RDW collision event was over, but it was still unstable and mainly affected by the shock waves produced at the start-up time. As the shock waves failed, the stable SRDW in Figure 8(c) was formed. That was the steady phase. How the multiple RDWs collided with each other to produce a single RDW was numerically explained in reference [22]. A short-time Fourier transform in Figure 8(d) for the pressure trace S1 was conducted, showing that the RDW frequency was $3920 \mathrm{~Hz}$. An RDW cycle of $0.255 \mathrm{~ms}$ was obtained from the frequency, very close to the RDW cycle of $0.256 \mathrm{~ms}$ directly obtained from the pressure trace.

Some pressure peaks of S1 and S2 during the transient phase in Figure 7(b) were coincident, indicating LPD occurred. The LPD cycle was about $0.410 \mathrm{~ms}$. It was assumed 

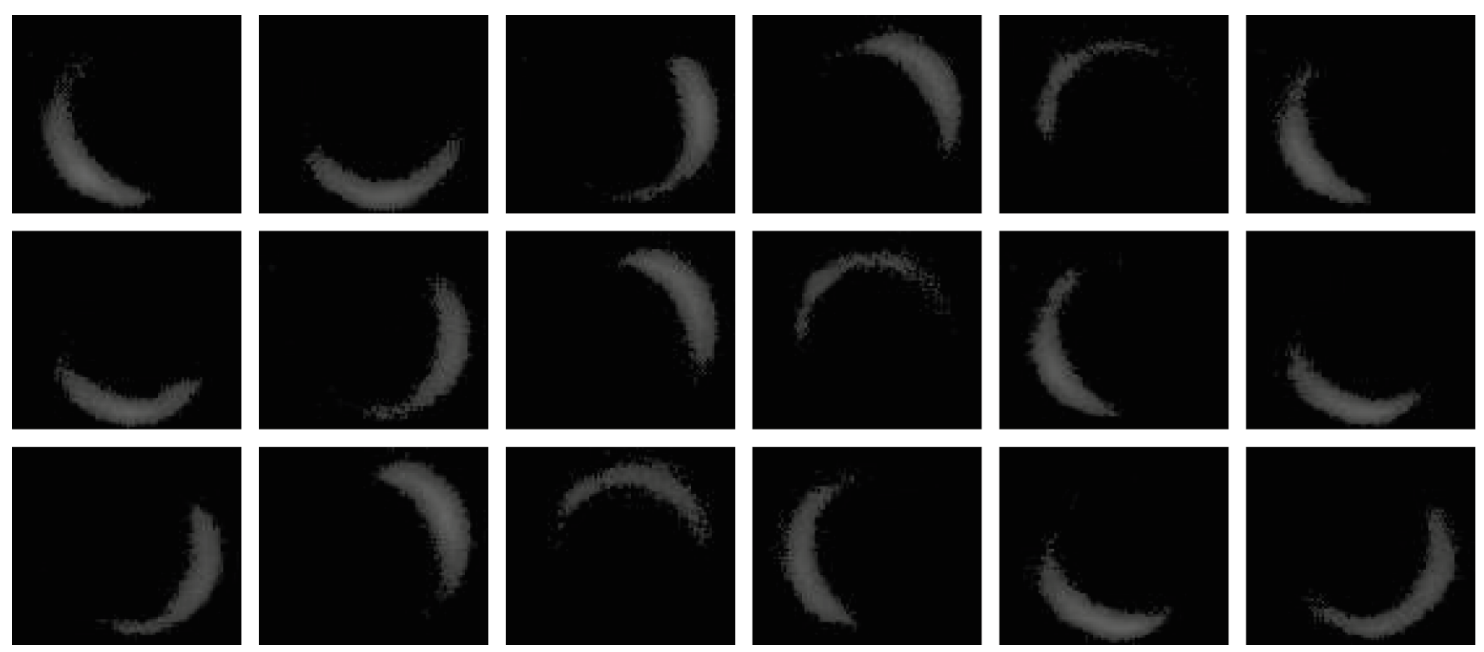

FIGURE 9: Continuous high-speed images for RDW rotating counterclockwise, $20000 \mathrm{fps}$ and air flow $708 \mathrm{~g} / \mathrm{s}$.

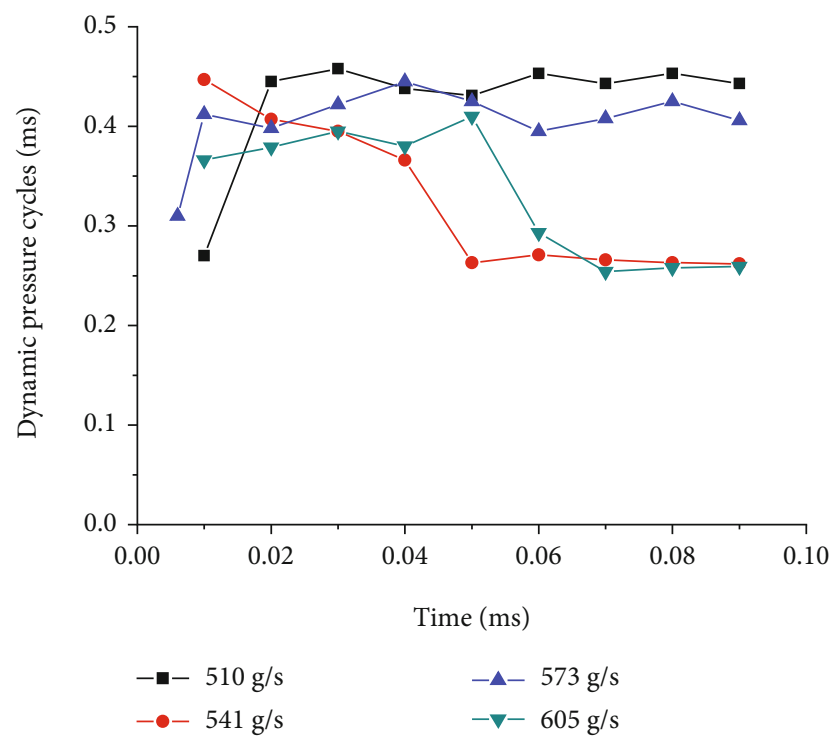

FIgURE 10: The RDW or LPD cycles as a function of time.

TABLE 2: The RDW velocity for the critical equivalence ratio at different hydrogen mass flow rates.

\begin{tabular}{lcc}
\hline $\begin{array}{l}\text { Hydrogen flow rate } \\
(\mathrm{g} / \mathrm{s})\end{array}$ & $\begin{array}{c}\text { Critical equivalence } \\
\text { ratio }\end{array}$ & $\begin{array}{c}\text { RDW velocity } \\
(\mathrm{m} / \mathrm{s})\end{array}$ \\
\hline 10.0 & 0.60 & 1210 \\
12.1 & 0.64 & 1217 \\
17.8 & 0.84 & 1212 \\
\hline
\end{tabular}

that an unknown shock wave intensifies the LPD, causing an explosion and the high transition peak in Figure $7(\mathrm{~d})$. Then, an RDW was formed due to the explosion inside the reactant. The reason for the run including a transient phase with LPD and a steady phase with a single RDW was well understood because the flow rate was at a point where the combustion mode changed from LPD and to SRDW, as shown in Table 1. The mode transition at critical points also explained

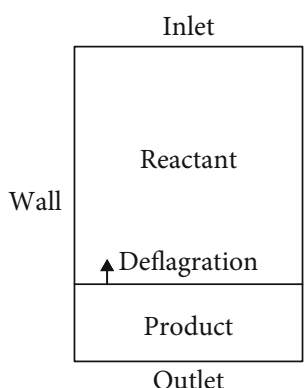

(a)

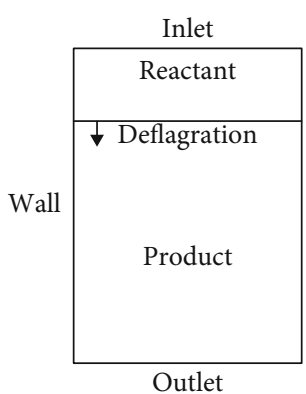

(c)

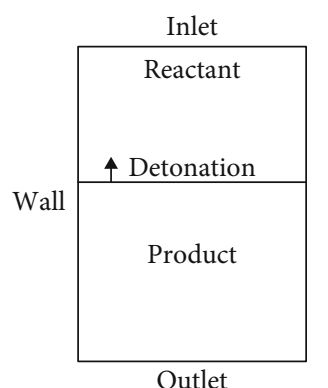

(b)

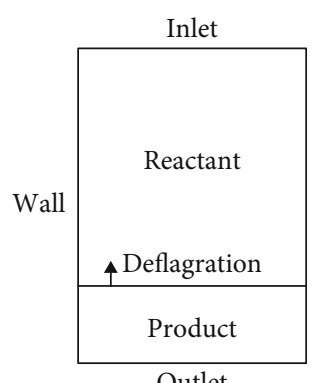

(d)
FIGURE 11: Schematic of generation mechanism of LPD.

why both the transient phase for the air mass flow rate $605 \mathrm{~g} / \mathrm{s}$ and the steady phase for $573 \mathrm{~g} / \mathrm{s}$ had the combustion mode of LPD, as shown in Figures 6(c) and 7(b). However, there was no LPD but rather an unstable SRDW during the transient phase for the run of the air mass flow rate $636 \mathrm{~g} / \mathrm{s}$, as further confirmed by the relationship between the high air flow rate and SRDW. It was concluded that a single RDW was formed from LPD or multiple counterrotating RDWs.

The continuous high-speed images (20000 frames per second, exposure time $1 / 20000 \mathrm{~s}$ ) during the steady phase in Figure 9 further identified the existence of one RDW rotating counterclockwise for the air flow rate of $708 \mathrm{~g} / \mathrm{s}$. The single RDW was stable, making for good combustion and propulsion performance. The single RDW in fuel-lean conditions 

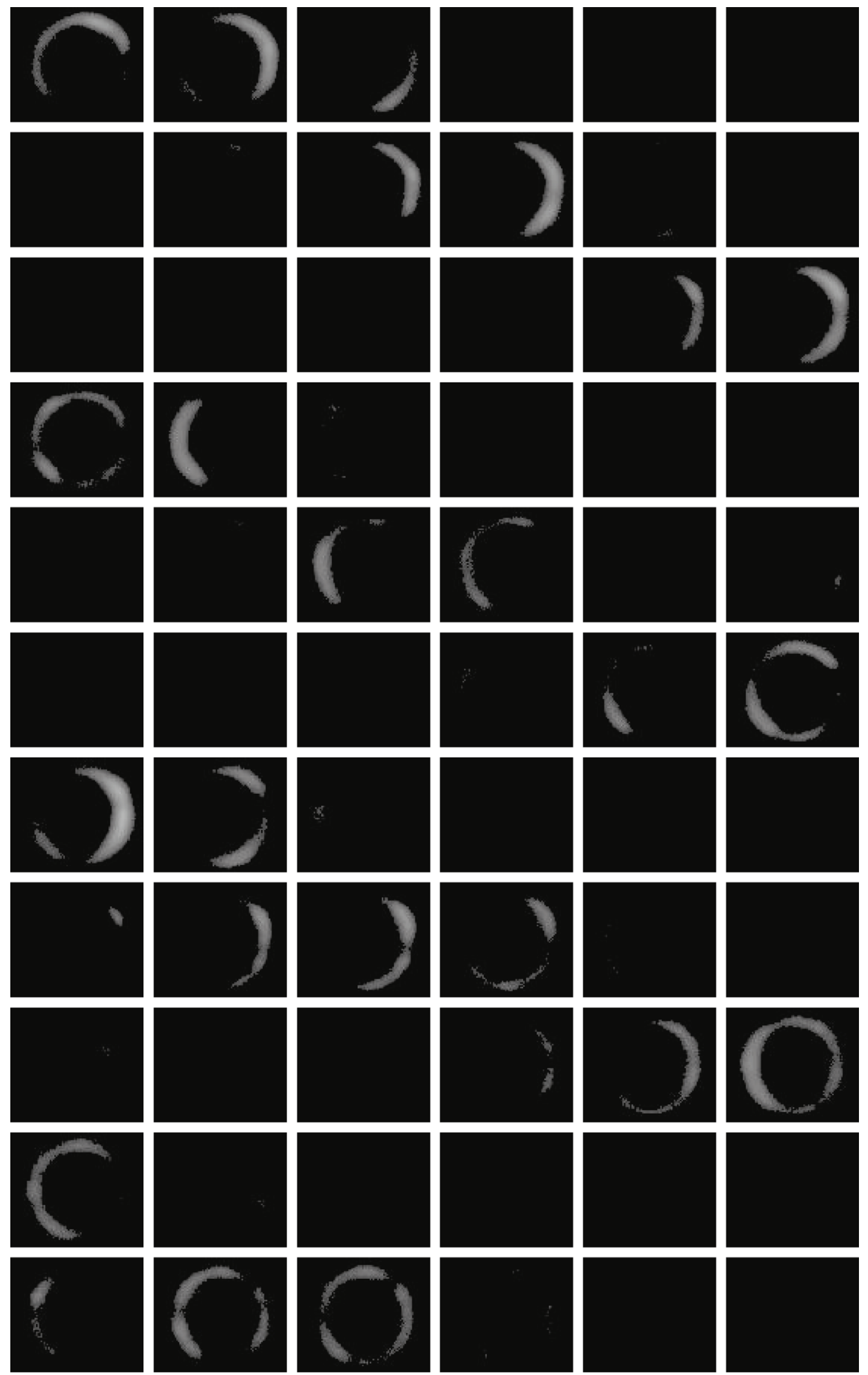

(a) Continuous high speed images

Figure 12: Continued. 


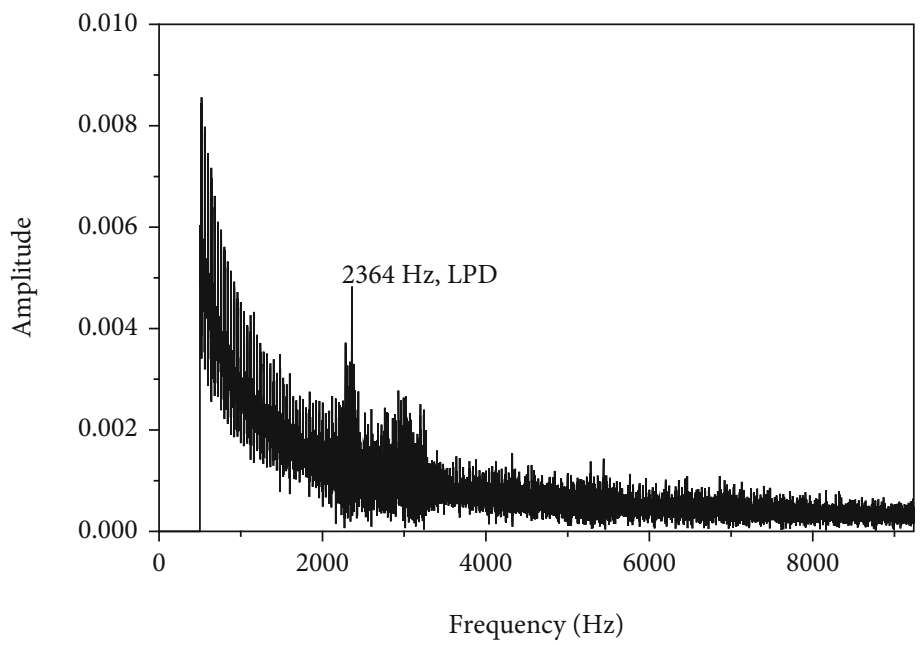

(b) Frequency domain analysis of the pressure trace

FIGURE 12: Continuous high-speed images and frequency domain analysis for LPD, $20000 \mathrm{fps}$, air flow $677 \mathrm{~g} / \mathrm{s}$, and equivalence ratio 0.62 [31].

in particular could be applied to air-breathing engines because the temperature inside the combustor is low and the exhaust plume is very short, an operating condition that would be helpful for infrared stealth.

The RDW or LPD cycles obtained from the pressure traces for some air flow rates are shown in Figure 10. The cycles for condition B were difficult to calculate because of the unstable RDWs and are not shown in Figure 10. A single RDW was produced after ignition for the air flow rates of 510 and $573 \mathrm{~g} / \mathrm{s}$ and resulted in a shorter cycle. Then, the cycles were increased because the unstable RDW turned to the case of a longitudinal pulsed detonation. However, the longitudinal pulsed detonation was formed during the transient phase and then turned to be a single RDW, causing the cycles of dynamic pressure to be decreased for air flow rates 541 and $605 \mathrm{~g} / \mathrm{s}$.

3.5. Tests at Other Hydrogen Flow Rates. In addition, tests at other hydrogen flow rates were performed and the critical equivalence ratio for the single RDW is shown in Table 2. When the equivalence ratio was less than the critical one, a single RDW occurred and it was a steady run. It seemed that the steady run of a single RDW had a greater critical equivalence ratio at higher hydrogen flow rates. The RDW intensity is increased with the increased flow rate. A stronger RDW is more stable when affected by unsteady flow and hence has a greater critical equivalence ratio. The hydrogen mass flow rate and equivalence ratio only slightly affected the velocity of the stable RDW for the present RDE.

3.6. A New Mechanism for LPD. The generation mechanism of LPD is proposed and shown in Figure 11. A counterrotating detonation wave tends to be initiated by a shock wave since the equivalence ratio for LPD is close to that for multiple counterrotating RDWs. At the beginning, an unstable RDW is usually formed after ignition, as shown in Figure 6(b). When the RDW is weakened by the counterrotating detonation wave, it will decay to be a deflagration blown downstream towards the outlet. The fuel-oxidant mix- ing becomes better downstream since the mixing needs time and a distance. When the deflagration comes to a position where the mixing is good enough for a detonation to be produced, a deflagration to detonation transition occurs and the deflagration or detonation moves upstream, as shown in Figures 11(a) and 11(b). The detonation wave is weakened gradually on the way to the inlet because the mixing of fuel and oxidant becomes less complete. The high-temperature products will be blown downstream after the collision between the detonation and inlet wall because the poor mixing cannot sustain a detonation front. The deflagration between the reactant and product in Figure 11(c) is being blown away. A deflagration to detonation transition occurs again for the same reason above, shown in Figure 11(d). One LPD cycle occurs between Figures 11(a) and 11(d). It is noted that the detonation wave is always moving upstream since the reactant is near the inlet, which causes a great loss in thrust. In conclusion, collisions of counterrotating detonation waves fail the original detonation, and upstream poor mixing and downstream good mixing sustain the LPD.

This mechanism is supported by the high-speed images and frequency domain analysis of the pressure trace in Figure 12 [31]. The test in Figure 12 employed the experimental setup in the present study. Detonation and deflagration occurred alternately, producing LPDs. Detonation produced the white zones, and there was no detonation in the black images in Figure 12(a). Actually, deflagration had a lower temperature than detonation, making the purely black images. Deflagration event with a lower temperature was not captured by the high-speed camera due to the short exposure time. If there had been no deflagration in the black images, detonation could not have been initiated anyhow. Seen obviously in Figure 12(a), deflagration time was much longer than detonation time, agreeing well with that in Figure 11. After all, detonation took up only a part of the time during which the combustion wave moved upstream. However, deflagration existed all the time when the combustion wave was blown downstream. As seen in Figure 12, the LPD lap time was corresponding to 8 images which took up 
400 microseconds, roughly according with the frequency $2364 \mathrm{~Hz}$ in Figure 12(b). The difference of time resolution between pressure sensors and the high-speed camera caused the frequency error.

\section{Conclusions}

$\mathrm{RDE}$ tests were conducted to study the effects of the equivalence ratio and air flow rate on the modes of combustion observed. The hydrogen flow rate was fixed to be $10 \mathrm{~g} / \mathrm{s}$. The tests simulated the effects of changing air flow on the engines during the flight.

(1) When the equivalence ratio was greater than 3.35, deflagration and diffusive combustion outside the combustor occurred and the propulsion performance was poor. When the equivalence ratio was $0.80-2.56$, multiple counterrotating RDWs occurred, which was not a desirable operating condition since the detonation was unstable. When the equivalence ratio was $0.60-0.80$, longitudinal pulsed detonation occurred

(2) LPD was not fully developed and caused great flow losses. Poor upstream mixing and good downstream mixing in the combustor sustained a regime of longitudinal pulsed detonation. Detonation and deflagration occurred alternately during an LPD lap and deflagration cost most of the lap time. LPD was produced near the combustor outlet due to the deflagration to detonation transition and moved to the combustor inlet. LPD failed near the combustor inlet due to the poor mixing, and deflagration formed from LPD failing was blown downstream. LPD was produced again near the combustor outlet. That is one LPD lap

(3) When the equivalence ratio was less than 0.60 , a stable single RDW was obtained, making for the best performance of all. A single RDW was formed from longitudinal pulsed detonation or multiple counterrotating RDWs. The single RDW at fuel-lean conditions was especially applicable to air-breathing engines because the temperature inside the combustor was low and the exhaust plume was very short, operating conditions that are helpful for infrared stealth

\section{Nomenclature}

DDT: Deflagration to detonation transition

LPD: $\quad$ Longitudinal pulsed detonation

MCRDWs: Multiple counterrotating detonation waves

RDE: $\quad$ Rotating detonation engine

RDW: $\quad$ Rotating detonation wave

RDC: $\quad$ Rotating detonation combustor

SRDW: $\quad$ Single rotating detonation wave.

\section{Data Availability}

Data is available on request.

\section{Conflicts of Interest}

The authors declare that they have no conflicts of interest.

\section{Acknowledgments}

This work was supported by the National Natural Science Foundation of China (Grant numbers 11702229, 11602207) and the Fundamental Research Funds for the Central Universities (Grant number buctrc201913).

\section{References}

[1] F. A. Bykovskii and E. F. Vedernikov, "Continuous detonation of a subsonic flow of a propellant," Combustion, Explosion and Shock Waves, vol. 39, no. 3, pp. 323-334, 2003.

[2] P. Wolanski, "Detonative propulsion," Proceedings of the Combustion Institute, vol. 34, no. 1, pp. 125-158, 2013.

[3] S. Zhou, H. Ma, D. Liu, Y. Yan, S. Li, and C. Zhou, "Experimental study of a hydrogen-air rotating detonation combustor," International Journal of Hydrogen Energy, vol. 42, no. 21, pp. 14741-14749, 2017.

[4] J. Kindracki, "Experimental research on rotating detonation in liquid fuel-gaseous air mixtures," Aerospace Science and Technology, vol. 43, pp. 445-453, 2015.

[5] F. Wang, C. Weng, Y. Wu, Q. Bai, Q. Zheng, and H. Xu, "Numerical research on kerosene/air rotating detonation engines under different injection total temperatures," Aerospace Science and Technology, vol. 103, article 105899, 2020.

[6] H. Wen, Q. Xie, and B. Wang, "Propagation behaviors of rotating detonation in an obround combustor," Combustion and Flame, vol. 210, pp. 389-398, 2019.

[7] Y. Zhong, Y. Wu, D. Jin, X. Chen, X. Yang, and S. Wang, "Investigation of rotating detonation fueled by the precombustion cracked kerosene," Aerospace Science and Technology, vol. 95, article 105480, 2019.

[8] Y. Wang, J. Wang, and W. Qiao, "Effects of thermal wall conditions on rotating detonation," Computers \& Fluids, vol. 140, pp. 59-71, 2016.

[9] D. Schwer and K. Kailasanath, "Physics of heat-release in rotating detonation engines," in 53rd AIAA Aerospace Sciences Meeting, Kissimmee, Florida, 2015.

[10] B. L. Naour, F. Falempin, and F. Miquel, "Recent experimental results obtained on continuous detonation wave engine," in 17th AIAA International Space Planes and Hypersonic Systems and Technologies Conference, San Francisco, California, 2011.

[11] F. Falempin and B. L. Naour, "R\&T effort on pulsed and continuous detonation wave engines," in 16th AIAA/DLR/DGLR International Space Planes and Hypersonic Systems and Technologies Conference, Bremen, Germany, 2009.

[12] K. Goto, J. Nishimura, J. Higashi et al., "Preliminary experiments on rotating detonation rocket engine for flight demonstration using sounding rocket," in 2018 AIAA Aerospace Sciences Meeting, Kissimmee, Florida, 2018.

[13] S. Claflin, S. Sonwane, E. Lynch, and J. Stout, "Recent advances in power cycles using rotating detonation engines with subcritical and supercritical CO2," in 4th International Symposium Supercritical CO2 Power Cycles, Pittsburgh, Pennsylvania, 2014.

[14] M. Fotia, F. Schauer, and J. Hoke, "Experimental study of performance scaling in rotating detonation engines operated on 
hydrogen and gaseous hydrocarbon fuel," in 20th AIAA International Space Planes and Hypersonic Systems and Technologies Conference, Glasgow, Scotland, 2015.

[15] B. A. Rankin, D. R. Richardson, A. W. Caswell, A. Naples, J. Hoke, and F. Schauer, "Imaging of $\mathrm{OH} *$ chemiluminescence in an optically accessible nonpremixed rotating detonation engine," in 53rd AIAA Aerospace Sciences Meeting, Kissimmee, Florida, 2015.

[16] K. Y. Cho, J. R. Codoni, B. A. Rankin, J. L. Hoke, and F. R. Schauer, "High-repetition-rate chemiluminescence imaging of a rotating detonation engine," in 54th AIAA Aerospace Sciences Meeting, San Diego, California, 2016.

[17] S. W. Theuerkauf, F. R. Schauer, R. Anthony, and J. L. Hoke, "Experimental characterization of high-frequency heat flux in a rotating detonation engine," in 53rd AIAA Aerospace Sciences Meeting, Kissimmee, Florida, 2015.

[18] S. W. Theuerkauf, F. R. Schauer, R. Anthony, D. E. Paxson, C. A. Stevens, and J. L. Hoke, "Comparison of simulated and measured instantaneous heat flux in a rotating detonation engine," in 54th AIAA Aerospace Sciences Meeting, San Diego, California, 2016.

[19] J. R. Codoni, K. Y. Cho, J. L. Hoke, and F. R. Schauer, "Mach disk pressure measurement technique within rotating detonation engine," in 52nd AIAA/SAE/ASEE Joint Propulsion Conference, Salt Lake City, UT, 2016.

[20] I. Q. Andrus, P. I. King, M. D. Polanka, F. R. Schauer, and J. L. Hoke, "Experimentation of a premixed rotating detonation engine utilizing a variable slot feed plenum," in 54th AIAA Aerospace Sciences Meeting, San Diego, California, USA, 2016.

[21] J. A. Suchocki, S. J. Yu, J. L. Hoke, A. Naples, F. R. Schauer, and R. Russo, "Rotating detonation engine operation," in 50th AIAA Aerospace Sciences Meeting including the New Horizons Forum and Aerospace Exposition, Nashville, Tennessee, 2012.

[22] Y. Wang, J. Yang, and C. Zhong, "Shock effects on rotating detonation waves in the hydrogen-air mixture," in 34th AIAA Applied Aerodynamics Conference, Washington DC, 2016.

[23] X. Tang, J. Wang, and Y. Shao, "Three-dimensional numerical investigations of the rotating detonation engine with a hollow combustor," Combustion and Flame, vol. 162, no. 4, pp. 9971008, 2015.

[24] D. P. Stechmann, S. D. Heister, and S. V. Sardeshmukh, "Highpressure rotating detonation engine testing and flameholding analysis with hydrogen and natural gas," in 55th AIAA Aerospace Sciences Meeting, Grapevine, Texas, 2017.

[25] R. Dyer, A. Naples, T. Kaemming, J. L. Hoke, and F. R. Schauer, "Parametric testing of a unique rotating detonation engine design," in 50th AIAA Aerospace Sciences Meeting including the New Horizons Forum and Aerospace Exposition, Nashville, Tennessee, 2012.

[26] C. Wang, W. Liu, S. Liu, L. Jiang, and Z. Lin, "Experimental investigation on detonation combustion patterns of hydrogen/vitiated air within annular combustor," Experimental Thermal and Fluid Science, vol. 66, pp. 269-278, 2015.

[27] V. Anand, A. St George, R. Driscoll, and E. Gutmark, "Longitudinal pulsed detonation instability in a rotating detonation combustor," Experimental Thermal and Fluid Science, vol. 77, pp. 212-225, 2016.

[28] S. M. Frolov, V. I. Zvegintsev, V. S. Ivanov et al., "Hydrogenfueled detonation ramjet model: wind tunnel tests at approach air stream Mach number 5.7 and stagnation temperature 1500
K," International Journal of Hydrogen Energy, vol. 43, no. 15, pp. 7515-7524, 2018.

[29] A. Naples, J. Hoke, and F. R. Schauer, "Rotating detonation engine interaction with an annular ejector," in 52nd Aerospace Sciences Meeting, National Harbor, Maryland, 2014.

[30] D. E. Paxson, "Examination of wave speed in rotating detonation engines using simplified computational fluid dynamics," in 2018 AIAA Aerospace Sciences Meeting, Kissimmee, Florida, 2018.

[31] Y. Wang, C. Wang, J. Le, and S. Huang, "Longitudinal pulsed detonation and rotating detonation in rotating detonation engines," in 5th detonation and new propulsion meeting, pp. 213-214, Changsha, China, November 2017. 